Continued from $p 161$

reaching a somewhat amiable solution when we heard of a much larger commotion nearby. A brawl had broken out down the road between some Afghani and Sudanese people. The factional nature of the camp was especially highlighted here and with the waning light we knew it was time to go.

\section{Unrelenting gendarmes}

The team, all 30 of us from different disciplines, had all collected together to make a safe exit. However, due to the arguments six of us had become split from the rest. We made our way to the main exit which had now been completely blocked by ranks of armed unrelenting gendarmes. When we approached, as unthreateningly as possible showing our aid worker badges, we finally realised the mentality of the French police towards not only the people here in the camp but also towards those who come to help. We were told that we had made our decision to be here and that we should now deal with it. The next time we would leave the camp would be the next morning and that it was nothing but our own fault. We tried in English, we tried in French but the result was still the same, nothing worked. One of the friends we had made in our time saw us and told us of an alternate exit at the other end of the camp.

With only around 30 minutes of sunlight remaining and a Eurotunnel slot to make we made a precarious move for the other exit, quick enough to get there before they closed that exit too yet slow enough so as to not attract any attention running through the camp. As we made our way through the factional nature of the camp was yet again underlined as we passed through a number of distinct areas and made it out just as the gendarmes were lining up on the road outside. Thankfully all members of the team made it out of The Jungle and back home to English soil safely. We never thought we'd be that pleased to see our own boys in blue again.

Overall, this trip was an incredible experience but one that highlighted the desperate conditions of these poor people. Their sheer resilience in spite of all the adversity they have faced and continue to face is genuinely emotional and inspiring. It is made worse with the knowledge that there doesn't seem to a political solution coming soon to help them. Despite their optimism, despite their faith, despite their goodbye wishes of 'I'll see you in the UK', it is hard to see a way out of these camps for them. The aid that we provided, little that it may have been, was honestly helpful and necessary. However, unless the refugees' situation changes they will be in need of help again in the near future. Everyone in this camp is in a form of welfare cycle where they start by being in need and they are then given help, whether it be medical, dental, tents, blankets etc. There is a period of acquiescence where their situation appears to be better but then they get another infection, the weather ruins more of their tents, their blankets are soaked yet again, they are hungry once more and then they back in need again.

Politically we choose our sides and fight for a way for this to end but no one can ignore the humanitarian aid that these people need just across the border. One weekend of work is not enough. One drop load of welfare is not enough. It is only through the regular and consistent provision of care that the refugees' situation will once again become bearable and we can truly help. If you would like to volunteer, please email salman.sheikh@kcl.ac.uk.

\title{
KING'S COLLABORATES WITH CHINA
}

King's College London and BYBO Dental Group, one of the largest dental providers in China, have announced a partnership that will see collaboration on clinical activities, staff exchange, transfer of clinical expertise and protocols, and continuing professional education.

Over the next three years, experts from King's Dental Institute will deliver lectures, seminars and clinical training in Shanghai, Beijing and Guangzhou to BYBO staff. Supplementary training will also be delivered through a number of blended learning and online CPD courses.

The collaboration will include BYBO clinical staff visiting King's London campuses for a programme of lectures and clinical visits. The programme will aim to equip BYBO staff with a greater understanding of clinical protocols, patient safety and quality control and will allow the two institutions to share best practice around establishing and managing oral health speciality centres. A number of King's dental experts will also be invited to attend the BYBO annual international academic forum in Beijing from 2016.

Professor Dianne Rekow, Dean of King's Dental Institute, said: 'Not only is [this] a fantastic opportunity to share our world-leading expertise with BYBO, but it also offers us a unique chance for us to learn from one of China's most renowned dental providers.'

BYBO Dental Group, based in Beijing, has over 75 clinics and hospitals in more than 30 regions in China, with a strong reputation in patient care and innovation.

The collaboration, worth $£ 3.6$ million, builds on a number of major healthcare initiatives between King's and Chinese organisations established in 2015. 